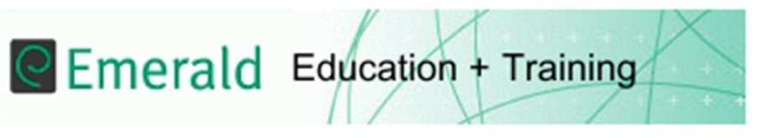

\title{
Forms of Graduate Capital and their Relationship to Graduate Employability
}

\begin{tabular}{|r|l|}
\hline Journal: & Education + Training \\
\hline Manuscript ID & ET-05-2016-0090.R3 \\
\hline Manuscript Type: & Research Paper \\
\hline Keywords: & capitals, higher education, skills, policy, Employability \\
\hline \multicolumn{2}{|l}{} \\
\hline
\end{tabular}

SCHOLARONE $^{\text {Ix }}$

Manuscripts 


\title{
Forms of Graduate Capital and their Relationship to Graduate Employability
}

\author{
Employability; capitals; higher education; skills; policy
}

\section{Introduction}

The issue of how and why graduates succeed in the labour market and what can be done to enhance their 'employability' continues to dominate discussions on the economic impact and role of higher education (HE). It is twenty years since the Dearing Report (1997) made active recommendations for the enhancement of graduates' 'employability skills' and calls for university curricula to be more attuned to the needs of the economy. Such concerns have been given a renewed momentum in light of recent UK government proposals linking institutional effectiveness and quality to graduates' returns in the labour market (DBIS, 2016). However, what makes a graduate desirable to employers and what role HE plays in this has been subject to considerable academic debate and employer analysis (Hinchliffe and Jolly, 2011). Whilst it is often assumed that graduates who possess the most desirable level of skills - or indeed 'attributes' - are more employable, much analysis has shown graduate employability to be broader and more complex (Jackson, 2016; Holmes, 2013; Tomlinson, 2012; Brown and Hesketh, 2004).

This article develops a new conceptualisation of graduate employability, based on graduate capitals. It conceptualises graduate employability as largely constitutive of the accumulation and deployment of a variety of interactive forms of capital. Capitals are defined here as key resources that confer benefits and advantages onto graduates. These resources encompass a range of educational, social, cultural and psycho-social dimensions and are acquired through graduates' formal and informal experiences. They also comprise multiple forms which interact and help reinforce the strength of each form. The main forms of capital which are integral to this approach are: human, social, cultural, identity and psychological. Much of the conceptual framings of capitals have been informed by either economic or sociological approaches which have highlighted the advantages of gaining formal qualifications and the favourable economic positioning this engenders. In the former case, overarching human capital accounts are popular amongst policy makers and make strong links between higher investments in learning and improved employment prospects and earnings. More sociological approaches (see Bourdieu, 1986) highlight the ways in which the relative acquisition of cultural capital, largely in the form of educationally and culturally-derived knowledge, generates educational (dis)advantage between individuals.

Whist these theories are relevant to the current conceptualisation, this article offers a more integrated and somewhat less causal approach; it also shows that whilst each of these components relate to different properties, they overlap to some degree and their boundaries are fairly fluid. More significantly, this article offers a new vocabulary to understanding graduate employability, its development in HE and in 
graduates' transition to the labour market. The article first considers the ways in which graduate employability has been commonly depicted through conventional notions of graduate 'skills'. It then outlines the main components of each form of capital, their salience to graduate employment and then some of the practical dimensions to developing these forms in and around HE.

\section{The dominance of the employability skills discourse}

Much of the current understanding of graduate employability, particularly in relation to the role of HE, has been framed around the enhancement of graduates' employability skills. Further developing graduates' employability skills, beyond their formal academic learning, is seen as a way of equipping them for meeting the challenges of graduate-level work. HEIs in particular have been very responsive to the language of skills adopted by employers and been prone to reproduce such discourse both in relation to institutional strategies and specific pedagogic initiatives (McCowan, 2015; Holmes, 2013). The discourse inflation on skills and attributes within HE would appear to have eclipsed even what employers have espoused on such matters.

A strong body of critical literature has emerged which illustrates various limitations of this approach. The first of these centres on a critical appraisal of the wider meaning and definition of skills and its bearing on the notion of employability. As James et al., (2013) argue, there is quite some difference between fairly homogenous 'graduate skills' and 'skills that graduates have'. The latter are not only highly diverse and context-specific, but also developed through multiple contexts and not just within HE. A crucial issue is the way in which they are further co-ordinated by employers, including the extent to which skills are able to be meaningfully deployed and further developed in graduates' working lives. Holmes (2013) has further challenged the overall conflation of graduates' purported 'possession' of 'skills' (and/or 'attributes') and their ability to secure employment on leaving HE.

Another body has critically examined the link between formal skills-centred provision and how much value these have on graduates' employment outcomes, including their overall relevance to employment settings (Mason et al., 2009; Wilton, 2011). Such evidence has pointed to the limited efficacy of skills initiatives, formally delivered in HE, on graduates' future employability. One of the issues, as the above research has illustrated, is the contextual barriers between formal university learning and the workplace and the degree to which acquired HE-level skills are either transferable or transversal. As Mason et al's review points out, any formally acquired employability skills cannot simply be transferred given that so many of the actual skills graduates deploy are derived from, situated in, and further generated through, the actual work context in which they are utilised.

More recently, calls have been made for a more nuanced conceptualisation of skills so that they encompass what actually impacts on graduates' post-university transitions. In attempting to move the broad schema of generic skills to more 
efficacious ground, Bridgstock (2009) has developed the notion of 'career management skills' which refer to the range of high-impact and longer-term careerssalient competences that have genuine purchase in graduates' post-university lives. This includes the abilities to purposively self-manage and proactively navigate future pathways. Jackson and Wilton's (2016) recent work on career management competences illustrates the significance of self-management and career insight, particularly in relation to graduates' ability to map-out future goals and the enhancement of their self-confidence and self-perceived employability. They discuss the importance of experientially-rich work-integrated learning for the nurturing of such competences, most of which are soft in form and potentially constitutive of graduates' lifelong learning.

This article departs from dominant skills approaches to employability and instead conceptualises employability as constituting a range of dynamic, interactive forms of capital which are acquired through graduates' lived experiences. The below model depicts two important dimensions for each form of capital: the key resources related to each and how they are utilised when graduates enter the job market. The possession of capitals is important, as is developing ways of enhancing them, but knowing how these have purchase and can assist graduates' entry to the labour market is likely to determine how effective they are for graduates' progression. The paper now examines each form as well as the practical dimensions associated with each.

\section{Figure 1: Graduate capital model here}

\section{Human capital - knowledge, skills and future performance}

Human capital refers to the knowledge and skills which graduates acquire which are a foundation of their labour market outcomes. This form of capital bears the closest relation to skills approaches given that it is concerned with what and how graduates can make connections between their formal education and future employment outcomes. The concept of human capital was developed by the economist Gary Becker (1993), who has referred to the 'marginal' productive value attached to higher level qualifications in the labour market. Human capital acquired through $\mathrm{HE}$ inculcates wider knowledge, technical and embedded, that graduates utilise in higher-end professional labour. In essence, the development of human capital in the form of formally acquired knowledge through higher levels of education and training empowers individuals in the labour market.

The strength of human capital, argue proponents of this approach, is that additional formal education makes individuals more skilled and therefore more productive. This has been a dominant tone in much UK skills formation policy based on the premise that greater participation in HE increases the collective level of investment in human capital and therefore the productive capacity of the overall workforce. There are clearly cases when specialist/technical knowledge is acquired by graduates that is applicable to their future employment and therefore enables them 
to access specific jobs. Such levels of occupational specificity reflect specialised knowledge and skills that reflect performance demands and expertise, for which formal education provides a key foundation.

Whilst the formation of occupationally-specific human capital remains important for graduates in a variety of vocational, specialist and certain STEM-related disciplines, in many cases the relationship between graduates' formal $\mathrm{HE}$ and future employment is looser. This is clearly the case in the UK, which compared to more occupational and regulated markets of Europe, offers less in the way of horizontal substitution of degree-related knowledge and future job-related specificities (Little and Archer, 2010). In such a context, 'what' a graduate has studied is often paramount for accessing specified occupational domains. Yet even if such graduates do not directly apply subject-specific knowledge, their higher level of academic training is perceived by employers to equip them with broader skills sets that can be converted productively when they enter working life.

\section{Practical dimensions of human capital}

University-acquired human capital may, in some instances, be tangible and transferable as in the case of those who have undertaken specialist programmes (e.g. medicine, nursing, law, accountancy). However, in the main, HE provides a general education rather than a specific training. Skills have purchase if they are applied in manifest ways which impact on graduate outcome and performance. If a graduate's employability is closely linked to the successful execution of a specific skill, then its acquisition and deployment are likely to have significance. However, whilst this may work in tightly-defined occupational areas where there is substitution between HE learning and labour market performance, in the UK's flexible labour market context such links are far less defined. One function of universities is to help graduates harness their knowledge in ways that frame its future economic utility. Working out which skills matter and how these align to targeted industries is clearly of significance, as is the capacity to demonstrate the productive value of generic knowledge.

Related to this is an awareness of the language of skills and finding ways of articulating skill sets and indicating how these may be applicable in future job settings. As Dacre Pool and Sewell (2007) have discussed, regardless of the ambiguous nature of skills, employers are at least receptive to this language, therefore making it important for graduates to be aware and able to communicate these back to employers. The key here is graduates' ability to exemplify the link between technical knowledge and subject specialism, as well as whatever generic skills they have acquired, and demonstrate how these may translate into future performance.

When applying notions of skills to graduates' post-university outcomes beyond fairly descriptive and check-list criteria, the notion of 'career-building skills' appear to have some purchase. As Bridgstock (2009) outlines, these represent some of the most apposite skills which graduates can develop both prior to entering and when 
transitioning to the market in terms of being able to exploit job opportunities. Career-building skills are based on types of knowledge (and related awareness) of not just employment-specific requirements but also wider labour market knowledge. This would encompass therefore career-related skills such as familiarity with one's target labour market (including trends, data, skills demand) and knowing how to apply for and access work (including CV development and entry requirement), as well opportunity awareness and exploitation.

\section{Social capital - networks and human relationships}

Social capital in relation to graduate employability can be understood as the sum of social relationships and networks that help mobilise graduates' existing human capital and bring them closer to the labour market and its opportunity structures. Social capital can shape and facilitate graduates' access and awareness of labour market opportunities and then being able to exploit them. Bourdieu's (1986) outline of social capital makes reference to the resources that individuals have access to as a result of their membership or connections to particular groups. Their participation in HE provides them with the basis to develop the necessary 'bridging ties' with other key social actors (Putnam, 1999). Such awareness is partly derived from experiences within the students' social and cultural milieu and linked to salient social influences, such as family and community members and peers. The important issue is finding ways of tapping into such resources in the pursuit of accessing employment.

Putnam's (1999) analysis of 'bonding' and 'bridging ties' is important to understanding the concept of social capital. Putnam (1999) conceptualised both 'bonding ties' - the interactions between members of a group that build and maintain cohesion and solidarity - and 'bridging ties' which refer to interactions external to the group. In relation to these ties, social capital is used to describe the resources that are made available to individuals or groups by virtue of networks and their associated norms and trust. These networks and norms are significantly enabling for they provide people with a potentially better-informed insight and understanding of what opportunities exists, where they reside, who the main gate-keepers are and what they need to access employment.

The concept of strong and weak ties has been advanced by Granovetter (1985) is also significant to analysis, referring to the strength of relational bonds individuals form at formal and informal levels. Crucial here is influence that such ties can generate in brokering trust, level of information and insider knowledge. Strong ties with immediate significant others (e.g. family members) in the forms of parental knowledge and networks may be one way of brokering awareness of employment opportunities, particular when rich sources of knowledge and information are transferred. However, Grannovetter's work emphasised the strength of weak ties in the form of a relatively thin spread of social connections and contacts- for example, emerging employer contacts - to be influential. The more points of social connection individuals are able to establish, from diverse and knowledge-enriching sources, the more knowledgeable and trusting they may become towards areas of social or economic life to which they may have been less familiar. 


\section{Practical dimensions of social capital}

The main issue at stake here for graduates' transition into employment is the ability to discern and then exploit opportunities, particularly when significant others in their lives have (or not) played a bridging role in helping them learn about and access employment opportunities. For instance, considerable policy attention is now given to the progression levels and labour market outcomes of students from lower socio-economic backgrounds (SMCPC, 2013), in light of continued underrepresentation of this group in elite professions.

It has become increasingly imperative for graduates to be able to develop bridging experiences and extend weak ties beyond the formal confines of university. One particularly salient facet of social capital formation concerns employer engagement, formal or otherwise, in the form of meaningful and gainful interactions between graduates and employers. Higher levels of employer engagement is likely to represent a clear bridging activity, not only through accessing valuable employer knowledge but also making graduates more directly visible to employers. A number of immediate ways of harnessing social capital through employer engagement can be encouraged. One is through direct contact with employers in ways that facilitate some level of reciprocal knowledge between an employer and graduate. Direct employer engagement through career fairs and online profile building (e.g. LinkedIn) are ways graduates can make themselves more visible to employers and enable early bridging to be formed.

Another form of employer bridging is through development of work experience, via internships or other forms of employment, which may establish crucial bridges between formal education and future employment - particularly if this provides rich knowledge or employment opportunities. Such activity will clearly advantage students if they wish to enter related fields of employment. Jones et al's (2016) research illustrated how school-leavers' work experience not only provided direct access to subsequent employment openings, but also helped generate more trusted and first-hand of knowledge about jobs and the measures need to enter and succeed in them.

There are other ways in which social capital can be harnessed. Whilst they may not typically perceive themselves as such, university careers practitioners are a potential source of weak ties for graduates. This may well be the case if knowledgeable and engaging practitioners are able to impart valuable knowledge on how to access particular fields of employment and build relations with employers. This extends guidance on approaching and better interacting with employers, particularly amongst those who are reluctant to approach employers. As the UK Future Track survey (2012) illustrates, there is a clear need for universities to better enhance networking opportunities and social capital amongst lower socio-economic students through extra-curricula activities and forms of employer engagement. 


\section{Cultural Capital: employability and cultural synergy and alignment}

Cultural capital can be conceived as the formation of culturally-valued knowledge, dispositions and behaviours that are aligned to the workplaces that graduates seek to enter. This concept was developed by Bourdieu $(1984,1986)$ who discussed the transference of such valued cultural knowledge between individuals' socio-cultural milieus and the educational context in which it was validated. This is further institutionalised through formal credentials whose status-enhancing functions provide privileged access to the labour market. This approach is still valuable, particularly when exploring how the relative acquisition and deployment of cultural capital, often formed outside of formal education, can provide access to employment (Bathmaker et al., 2013; Burke, 2015). However, in the context of mass higher education, formally institutionalised cultural capital signalling elite achievement and knowledge formation may be less potent in shaping access to employment. In mass $\mathrm{HE}$, the so-called 'field rules' between higher education and the labour market have shifted in terms of what currencies graduates potentially trade off in the market.

There are a number of components to the cultural capital approach which continue to have relevance, partly explaining why some graduates fare better when trying to break into various employment fields. One relates to the notion of distinction which Bourdieu developed, referring to added-value knowledge, tastes and achievements acquired through a range of cultural contexts and which potentially enrich an individual's social standing. If higher levels of education no longer signal such distinction, graduates have to do more in the way of developing these through and beyond higher education. The importance is finding how this is valued in the cultural domains of a targeted employer organisation. Lindberg's (2013) research on graduate medics, for example, illustrated how various forms of symbolic capital are valorised in elite occupational contexts and help graduates stand apart. His research cites examples such as prizes won, conferences attended, as well as other wider achievements, that confer value-added onto graduates and help in the recruitment process.

Another dimension of the cultural capital concept applicable to graduate employability is the concept of embodied capital, which is the manifestation of individuals' desired embodied behaviours and dispositions within a given field. This again is not likely to be ascribed similar value across the many occupational fields that graduates enter. For instance, a graduate sales manager may be encouraged to develop and present a form of embodied capital that is different to that encouraged for a graduate social worker. Thus, the deployment of embodied forms of capital is largely referenced against the values and social mores of any specific sector and organisation, and the types of field dynamics by which it operates. Embodied behaviours desired within profit-making organisations may be quite different to those in public or third sector contexts. In all cases, the ability to demonstrate the interpersonal and behavioural expectations of a specific organisational field is important. The demonstration of appropriate forms of embodied capital via accent, body language, humour and the overall 'personality package' is therefore significant. 


\section{Practical dimensions of cultural capital}

The challenge to this mode of capital is that it is differentiated across the student and graduate population, which may be reinforced through mass HE. One of the salient findings from research by Bathmaker et al. and Burke on graduates from different socio-economic backgrounds is the different understandings of field rules, as well as knowledge and confidence in being able to negotiate them. This is also manifest in decisions and orientations, including in the case of lower socio-economic graduates, precluding areas of the job market that their middle class colleagues may feel comfortable in approaching. Likewise, the intangible, interpersonal qualities which employer research has shown to make a discernible impact on recruitment decisions (Brown and Hesketh, 2004; Hincliffe and Jolly, 2011; Morley, 2007; McCracken et al., 2015) also appear strongly connected to graduates' wider cultural make-ups.

There is clearly a need for institutions to think creatively about how to enhance cultural capital amongst their students. A key issue relates to processes of cultural unfreezing and expanding the realms of the possible, including the development of personal confidence and horizon scanning. The cultural exposure approach, based on building potential students' confidence and self-perceptions of value, has been a key feature of widening participation (for example, Aim Higher in the UK). This is predicated on the principle that if students are exposed to institutional cultures, including its key cultural actors - i.e. current students, academics and managers this will challenge their constraining impressions and potentially expand their horizons.

One of the applications of this in work settings is building up stronger levels of cultural understanding and confidence towards targeted employer organisations. This is likely to necessitate greater cultural exposure and awareness of targeted work organisations which is where stronger interactions with employers, either through informal networks and internships or work experience can play a role. Such developments have been reported in a number of studies on school leavers' employer engagement episodes (Jones et al., 2016). Key outcomes arising from such interaction include the enhanced personal confidence, stronger visioning of potential new pathways and motivation to achieve. Cultural capital enhancement is directly sourced in such contexts through actual experiences that provide graduates' with stronger levels of cultural knowledge and understanding of targeted employment. Whilst formal technical knowledge of employer organisations may be significant in harnessing technical-fit and giving both graduate and employer a stronger sense of profile alignment, this often needs to be complemented with relevant cultural knowledge. The latter involves awareness of cultural practices and orientations as well as values and behavioural mores.

Once perceptual bridges have been formed through stronger cultural knowledge and awareness, graduates will need to embody this in the form of behaviours and attitudes that convey cultural synergy. Some graduates, including those from lower socio-economic background and lower-ranked HEIs may encounter stronger 
challenges, and potential set-backs, in this regard (Greenbank, 2011; Morrison, 2014). Further issues reported in such studies relate to such graduates' tendencies to downplay wider achievements, particularly those which signal value-added distinction. Yet it may be the case that employer engagement in such institutions can go some way towards graduates becoming more aware of, and presenting more effectively, wider life and employment experiences in advantageous ways. Formal recruitment training can further help in this regard, particularly interview coaching, whereby graduates are given opportunities to harness embodied dispositions and behavioural competences which better fit employers' recruitment practices.

\section{Identity capital: self-concept and personal narratives}

Identity capital is defined here as the level of personal investment a graduate makes towards the development of their future career and employability. This also extends to the levels to which they can draw on experiences and articulate a personal narrative which aligns to the employment domains they seek to enter. The key here is a graduate's capacity to develop emerging identities and then warrant and perform this in the early stages of the labour market. Such formation is likely to provide advantages if the personal investment people make toward future work propel them actively towards the labour market. The self-perception and selfconcepts graduates form around future work can therefore provide a frame through which they may be able to channel their experiences and profiles.

Both general sociological and sociology of work literature have illustrated the importance of sustaining a narrative of self, particularly in increasingly individualised and fluid economic conditions (Giddens, 1991; Beck and BeckGermsheim). Sociology of work literature has shown the multiple ways in which identities are formed (or deformed) through the organisational cultures in which are negotiated. Much of this is to do with active assemblage of self-images and behaviours, which are derived from broader discursive constructions around what constitutes a desirable and valued employee (Du Gay, 1996; Marks and Thompson, 2010; Strangleman, 2012). Identity capital has been defined by Cote thus: "the process of identity capital acquisition describes how the individual invests in a certain identity (or identities) and engages in a series of exchanges with others in a variety of contexts (only some of which are economic") (Cote, 2005, p225).

The potentially significant role of identity formation, as well as other psycho-social dimensions, has been increasingly acknowledged in broader career management literature and that relating to graduate careers (Fugate et al., 2004; London, 1993). London refers to career identity as the extent to which a career is an integral part of an individual's personal identity and its centrality to their life as a whole. It also entails their overall sense of commitment towards developing a career in terms of being psychologically contracted to particular jobs and organizations. In graduate employability research and analysis, identity has been shown to play an important role in how graduates negotiate access to employment, mainly through recruitment. In Hinchliffe and Jolly's (2011) analysis, identity is presented as a contextuallysignificant component of behaviours and value sets required in specific 
organisational domains. These researchers nest graduate identity around the four core elements - values, social engagement, intellect and performance - all of which need to be presented and warranted through discourse and action.

The issue of identity warranting has been extensively developed by Holmes (2013; 2015) in his graduate identity model which centres on the emergent identities graduates have developed about their future role and capability have to be warranted or socially affirmed by others. The experience of recruitment or early appraisal of performance may be crucial here, potentially affirming or spoiling the early ideas graduates had about a job and their role within it. The extent to which graduates can build identities, and related identity capital, therefore has a strong bearing on their progression during early stages of the labour market.

Further pertinent analysis has been advanced by Jackson (2016) who elaborates the concept of 'pre-professional identity' as a key component of graduates' early professional development and formation. This is where HE curricula and learning have a potentially significant role to play, helping graduates to develop selfperceptions and goals which may form part of their wider career development. In Jackson's conceptual outline, pre-professional identities are developed through the wider 'landscapes of practice' which universities provide. In seeing HE as a landscape of practice, graduate development is not confined to walled disciplinary communities, but can also encompass interactions with employers, career services, extra curricula engagement and other forms of experiential learning. The closer such experiences actually align to future lives, the more empowering and self-forming they become and enable a graduate to project a self-image towards areas of working life.

\section{Practical dimensions of identity capital}

If the emerging identities graduates form impel them towards thinking proactively and imaginatively about their future careers and employability then finding ways of developing these may have some significant impact on their immediate futures. Previous research indicates that students who invest more strongly in their careers tend to show higher level of identity capital (Tomlinson, 2007) - future careers are a strong part of their on-going and anticipated future 'life project'. Finding ways of enhancing students' self-perceptions and emergent identities so that they form more cohesive and crystallised career goals may be significant in shaping the early management of their employability. Jackson (2016) has discussed the importance of the informal dimension of the university experience for work-related identity, particularly students' interactions through higher education's diverse experiential offerings. It appears important therefore that identity formation moves beyond simply a formal disciplinary milieu.

The other key issue relates to graduates' ability to lay claim to the emergent identities they carry forward to the labour market as depicted in Holmes' $(2013,2015)$ research. As Holmes argues, students need to be encouraged to be able to translate potential identities into manifest evidence of the future behaviours and 
performances that these identities are meant to embody. Rather than merely reproducing the description of skills, the task becomes more one of demonstrating or warranting how these constitute practices appropriate to future work-related roles and practices. Enabling students to develop this capacity may be crucial if they are to demonstrate alignment between emergent identities and future performance within a specific working context.

The significance of self-presentation or the projection of an emerging employability narrative which is attractive to employers relates to another salient mode of identity projection: the CV. Miller and Morgan (1993) have conceptualised the CV as an autobiographical practice, highlighting the significance of projecting and promoting one's relative employment value through lived experiences. In effect, the CV becomes a key tool through which individuals encapsulate a formal presentation of self through their accounts of their employment, and related autobiographical, narratives. If marketability is now a significant component of employability then graduates need to be primed in the ability to present a compelling employability narrative that conveys their identities. The accumulation of work-related achievements and experiences in turn become markers of potential organisational value. It is clear from research on students' use of extra curricula activities that many are now using this as a vehicle towards presenting a wider account of themselves, in turn providing a competitive edge compared to other graduates with identikit educational profiles (Roulin and Bangerter, 2013).

\section{Psychological capital: resilience and career adaptability}

Psychological capital is a potentially significant form of capital as it is based on the psycho-social resources which enable graduates to adapt and respond proactively to inevitable career challenges. The level of challenge and adversity has clearly increased for graduates leaving higher education and fewer graduates expect the process of finding employment to be straight-forward. Of increasing importance is graduates' level of adaptability, not only in terms of navigating more uncertain terrain, but also withstanding challenges and set-backs such as potentially sustained periods of under-employment and unemployment (Fugate et al., 2004). The notion of career adaptability as developed by Savikas and Porfeli (2012) refers to individuals' capacities to respond and adapt to change and flux across working lives. Other research (Brown et al., 2012) has illustrated the importance of various forms of career adaptability-related learning for managing challenge across work transitions, including learning from others, level of challenge and being open to novel experience. As this research highlights, greater levels of career adaptability enable individuals to more readily re-orientate goals and make more proactive decisions when encountering de-stabilising job market experiences.

There are a number of constituent dimensions to psychological capital, one of which is problem-focused coping towards developing proactive strategies in the face of challenge, mainly in the form of learning from experience. The key issue at stake is how well individuals are able to withstand what is likely to be inevitable pressure and set-backs over the course of a career, as well as how flexible they are. Much of 
the psychological capital concept has roots in the positive psychology literature and is associated with researchers such as Seligman (1998). At the core of this concept is an individual's capacity to adapt to challenge personal circumstance and establish a relatively high locus of self-control. Chen and Lim (2012) locate the concept of psychological capital in the context of job adversity, such as loss of a job or sustained unemployment, as well more widely to a volatile and competitive climate. In the case of graduates seeking top-end forms of employment, high performance expectations and sheer intensity of work is likely to create considerable emotional demands. These researchers highlight some of main benefits of developing strong levels of psychological capital, from higher overall self-perceived employability and job search behaviours, through to productive coping strategies.

Self-efficacy is clearly important, not only in terms of graduates' self-perceived ability to accomplish career goals but also the capacity to withstand adverse conditions. Another key issue is resilience in terms of withstanding pressures and disruptions in the initial stages of their careers in a potentially uncertain and volatile climate. Stronger resilience enables graduates to adapt to challenging labour market situations, including periods of unemployment and under-employment or the case of disappointment in the forms of job rejection or unanticipated challenge. The more psychological capital graduates can develop, the more proactive and adaptable is likely to be their response in such circumstances.

\section{Practical dimensions of psychological capital}

Some of the dispositions related to psychological capital are more abundant in some graduates than others. Other related elements of psychological capital, including enabling mind-sets, openness to experience and risk tolerance may also further mediate how potentially adverse job market circumstances are dealt with. Whilst it may not be a straight-forward task for those working in higher education to develop a graduate's adaptability and resilience levels, there are ways of promoting its significance when transiting to paid employment. The more graduates are able to internalise the significance of managing their responses to career challenge the more equipped they may become at managing adverse situations (Koen et al., 2012).

Two key practical concerns arise on the theme of career adaptability. One relates to the increasing necessity of flexible contingency planning in early career management and guidance and the other is around expectation management and coping mechanisms for inevitable stress and set-back. The first resonates with much of the contemporary literature on career change, sometimes referred to as 'protean career' pathways (Baruch, 2014). Practitioners may need to raise awareness of the increasing movement towards this and frame a graduate's career goals less around single jobs and job markets and more around a range of pathways, some of which may not be linear and clearly-defined. If, as identity researchers have pointed out, emerging identities can easily get spoiled early on then a graduate will need to reformulate and re-appraise their goals and think proactively and in ways which allow them to re-adapt to new employment fields. 
There is a clear need for practitioners to help manage expectations around an education-work transition that might increasingly be understood as a 'reality shock' (Kramer, 1974). If graduates are primed to believe that, after a relatively smooth (and, in many cases, successful) experience through prior education they will fall seamlessly into chosen pathways this may intensify the level of challenge and apprehension when faced with experiences discordant with these expectations. A key issue here is expectation management and the promotion of related mind-sets around flexibility and career malleability. There is clearly need for those working in higher education to establish the importance of resilience and ways of proactively managing what are likely to be less linear and stable pathways during early careers and beyond.

\section{Discussion and synthesis}

Higher education institutions continue to be ascribed a significant role in developing graduates' employability and future labour market prospects. The policy imperative around this has recently intensified (DBIS, 2016). The challenges this brings to higher education, as well as the strong supply-side orientation to these policy goals, has been given critical attention (Wilton, 2011; McQuaid and Lynsey, 2005). There is, however, a need to think more broadly and conceptually about graduate employability and introduce new vocabularies that connect with its relational complexities and also graduates' lived experiences through and beyond higher education. This article has presented a novel approach, one which combines many different facets of students' and graduates' formations of skills, knowledge, social relations, cultural praxis, identities and psycho-social dispositions. The forms of graduate capital outlined here are conceived as crucial resources which are cumulative and recursive in nature, potentially empowering graduates when making the transitions. The formation and application of capitals further potentially expands the parameters of their choices and capacity to act in economically advantageous ways. At their most direct level, they can inform a graduate's immediate relations to the job market and shape how they and others perceive their potential and scope.

This approach may enable us to think creatively towards resolving continued tensions between relative (dis)advantages emerging from different graduates' familial and socio-economic background and the affordances of higher education. $\mathrm{HE}$ is clearly not in a position to compensate for either changing economic realities or engrained social inequalities. It can, however, offer emancipatory scope; not only in terms of graduates' intellectual development but also their access to equitable employment. One of the main features and strengths of the capitals approach is its emphasis on the significance of multiple resources which are constitutive of employability, which are acquired across various domains and are not simply confined to formal educational provision. Capital formation is also therefore processual and relational in the sense that capitals are acquired and deployed over time and their effects sustained across a range of employment-related contexts. 
Crucially, different forms of capital feed off, and enrich, other forms. Human capital is clearly foundational for graduate-level employment, both specific and general. But this alone is insufficient and needs to be complemented by other capitals in terms of being socially operationalised in the wider employment milieu in which it is applied. The mobilisation of human capital and its related hard skills and other career-related skills is achieved through the necessary interactions which graduates have to make with significant others in the labour market. It effectively becomes socialised through social relations which facilitate access to jobs and enable skills and credentials to be recognised and potentially utilised. This social capital in turn needs to be channelled through the more culturally and interpersonally-mediated relations between graduate and employer. This centres on the inevitable cultural dynamics integral to the ways graduates negotiate access to employment, entailing the deployment of employment-specific cultural capital and their acceptance by employers. These processes in turn are not detached from more social-psychological and subjective processes involving graduates' more immediate responses to the employment process. Thus, whilst identity and psychological capital are more personal forms, they can be generative and also influenced by, as well as influencing, other capital formations. An example here would be a graduate lower in identity capital who may be less prone to making personal investments in future employment which, in turn, may serve to lessen the impact of his/her formal human capital, as well as their ability to mobilise this through the formation of wider social relations.

There are a number of united themes in this approach which also connect with other literature on the development of graduate employability, including how higher education experiences might thus contribute. Salient issues emerging from discussion are around employability development through capitals formation, include:

- The multi-faceted nature of HE and its many institutional offerings which help constitute graduates' development in numerous ways - academic, pastoral, cultural, political and social.

It is this context, which Jackson aptly describes as the 'landscape of practice' - seen in terms of the multi-layered, interacting component communities - which can make up a HE experience. It is through various communities that multi-modal forms of learning and personal development occur and where capitals are nurtured. The emergence of professional networks via, for example, employer engagement or work-integrated learning can be advantageous especially if they provide opportunities for greater exposure to, and confidence around, professional labour market.

Another related issue is:

- The significance of experience, particularly narratives of experience, upon which different capitals are formed. 
A salient theme here is the continued significance of work experience as an important dimension of capital formation and one which cuts across its many forms. Whilst work experience is a way of acquiring further work-related skills, it serves a wider function in bridging the HE-employment link. It also further enables graduates to build up a personal relationship to working life that enriches employability narratives, as well as contributing to the potential formation of early identities (Wilton, 2012; O'Connor and Bodicoat, 2016). The evidence therefore indicates that internships and other forms of paid employment can be useful for bridging existing links between study and the labour market and is valued by graduates, including those with less familial-derived social and cultural capital.

This also connects to:

- The importance of accessing, presenting and capitalising on experience and being aware of how these can be used for one's advantage:

Such experiences, as well as the ones students have acquired in and around formal university are crucial in the development of capitals. So-called extra-curricula activities are better framed around the enhancement of graduates' identity capital than 'transferable skills': the key is packaging and presenting them in ways that signal to employers distinctive personal value. In competitive and congested markets, this has become increasingly paramount. Experiences that can confer advantages in helping build graduates' capacity to articulate personal narratives needs to be captured and presented. When accessing target employment, graduates must embody this and convey it in ways that convince employers that is aligned to their own practices.

There is a potentially significant role for careers educators to facilitate graduates' abilities to exploit and lay claim to the labour market value of experiences and encourage them to frame these in advantageous ways. This continues to be the case for graduates, particularly lower socio-economic groups, and in some cases female students (Stevenson and Clegg, 2012), who appear to make less of wider achievements or package them as positional assets. Crucially, a new vocabulary, if channelled effectively by HE practitioners, can potentially have significant purchase amongst students and graduates and be used to frame the management of their employability.

\section{Acknowledgments}

I would like to thank various members of the Careers and Employability Service at the University of Southampton, in particular Hazel McCafferty, Helen Fuge and Kathryn Woods, for some helpful discussions related to this approach. 


\section{$\underline{\text { References }}$}

Baruch, Y. (2014), "The development and validation of a measure for protean career orientation", The International Journal of Human Resource Management, Vol. 25 No. 19, pp. 2702-2723.

Bathmaker, A.M., Ingram, N. \& Waller, R. (2013), “Higher Education, Social Class and the Mobilisation of capitals: recognising and playing the game", British Journal of Sociology of Education, Vol. 34 No. 5/6, pp. 723-743.

Beck, U. and Beck-Gernsheim, E. (2002), Individualization, Sage, London.

Becker, G.S. (1993), Human Capital: theoretical and empirical analysis with special reference to education (3 ${ }^{\text {rd }}$ Edition), University of Chicago Press, Chicago.

Bourdieu, P. (1984), Distinction: a social critique of the judgement of taste, Mass, Harvard, Cambridge.

Bourdieu, P. (1986), “The Forms of Capital”, In J. Richardson (Ed.), Handbook for Theory and Research for the Sociology of Education, Greenwood, Westport, CT,

Bridgstock, R. (2009), “The graduate attributes we've overlooked: enhancing graduate employability through career management skills", Higher Education Research and Development, Vol. 28 No.1, pp. 31-44.

Brown, A., Bimrose, J., Barnes, S.A. \& Hughes, D. (2012) “The role of career adaptabilities for mid-career changers", Journal of Vocational Behavior, Vol. 80 No. 3, pp. 754-761.

Brown, P. \& Hesketh, A. (2004), The Mismanagement of talent, Oxford University Press, Oxford.

Burke, C. (2015), Culture, Capital and Graduate Futures: degrees of class, Routledge, London.

Chen, D. and Lim, V. (2012), "Strength in Adversity: the influence of psychological capital on job search", Journal of Organzational Behavior, Vol. 33, pp. 811-839.

Cote, J. (2005), "Identity capital, social capital and the wider benefits of learning generating resources facilitative of social cohesion", London Review of Education, Vol. 3 No. 3, pp. 221-237.

Dacre Pool, L,. \& Sewell, P. (2007), “The key to employability: developing a practical model of graduate employability", Education + Training, Vol. 49 No. 4, pp. 277-289 
Dearing, R. (1997), The Dearing Report: Report for the National Committee of Inquiry into Higher Education: Higher Education in the Learning Society, London, HMSO

Department for Business, Innovation and Skills (2016), Success as a Knowledge Economy: teaching excellence, social mobility and student choice, HMSO, London.

Du Gay. (1996), Consumption and Identity at Work, Sage Publications, London.

Fugate, M., Kinicki, A.J. and Ashforth, B.E. (2004), “Employability: a psycho-social construct, its dimensions and applications", Journal of Vocational Behavior, Vol. 65 No. 1, pp. 14-38.

Future Track (2012), Transitions into employment, further study and other outcome: The Future Track Stage Report 4, Warwick Institute for Employment Research, Warwick.

Giddens, A. (1991), Modernity and Self-identity, Polity Press, Cambridge.

Granovetter, M. (1985), "Economic Action and Social Structure: the problem of embeddeness", American Journal of Sociology, Vol. 91 No. 3, pp. 481-510.

Greenbank, P. (2011), "'I'd rather talk to someone I know'- the role of network in undergraduate career decision-making", Research in Post-compulsory Education, Vol. 16 No. 1, pp. 31-45.

Hinchliffe, G. and Jolly, A. (2011), "Graduate Identity and Employability", British Educational Research Journal, Vol. 37 No. 4, pp. 563-584.

Holmes, L. (2013), “Competing Perspectives on Graduate Employability: possession, position or process?", Studies in Higher Education, Vol. 38 No. 4, pp. 538-554.

Holmes, L. (2015), "Becoming a graduate: the warranting of an emergent identity", Education + training', Vol. 57 No. 2, pp. 219-238.

Jackson, D. (2016), "Re-conceptualising graduate employability: the importance of pre-professional identity", Higher Education Research $\mathcal{E}$

Development .doi.org/10.1080/07294360.2016.1139551

Jackson, D. \& Wilton, N. (2016), “Developing career management competencies among undergraduates and the role of work-integrated learning", Teaching in Higher Education, Vol. 21 No. 3, pp. 266-286.

James, S., Warhurst, C., Tholen, G. and Commander, J. (2013), "What we know and what we need to Know about Graduate Skills", Work, Employment and Society, Vol. 27 No. 6, pp. 952-963. 
Jones, S., Mann, A. \& Morris, K. (2016), “The 'Employer Engagement' cycle in secondary education: analysing the testimonies of young British adults", Journal of Education and Work, Vol. 29 No. 7, pp. 834-856.

Koen, J., Klehe, U.C. and Van Vianen, A.E. (2012), “Training career adaptability to facilitate a successful school-to-work transition", Journal of Vocational Behavior, Vol. 81 No. 3, pp. 395-408.

Kramer, (1974), Kramer M. (1974), Reality Shock: Why Nurses Leave Nursing. C.V. Mosby Company, St Louis.

Lindberg, O. (2013), “Gatekeepers of a profession: employability as capital in the recruitment of medical interns", Journal of Education and Work, Vol. 26 No. 4, pp. 431452.

Little, B. and Archer, L. (2010), "Less time to study, less well prepared for work, yet satisfied with higher education: A UK perspective on links between higher education and the labour market", Journal of Education and Work, Vol. 23 No3, pp. 275-296.

London, M. (1993), "Relationships between career motivation, empowerment and support for career development", Journal of Occupational and Organizational Psychology, Vol. 66 No.1, pp. 55-69.

Marks, A. and Thompson, P. (2010) "Beyond the blank slate: identities and interests at work", in P. Thompson and C. Smith (Eds), Working Life: renewing Labour Process Analysis, London, Palgrave.

Mason, G., Williams, G and Cramner, S. (2009), "Employability skills initiatives in higher education: what effects do they have on graduate labour market outcomes?" Education Economics, Vol. 17 No. 1, pp. 1-30.

McCowan, T. (2014), "Should Universities Promote Employability?,Theory and Research in Education", Vol. 13 No. 3, pp. 267-285.

McCracken, M., Currie, D., and Harrison, J. (2015), “Understanding graduate recruitment, development and retention for the enhancement of talent management: sharpening 'the edge' of graduate talent", The International Journal of Human Resource Management, Vol. 27 No. 22, pp. 2727-2752

McQuaid R.W., and Lindsay C., (2005), "The Concept of Employability”, Urban Studies, Vol. 42 No.2, pp. 197-219.

Morley, L. (2007), “The X factor: employability, elitism and equity in graduate recruitment", Twenty- First Century Society, Vol. 2 No. 2, pp. 191-207. 
Morgan, N. \& Miller, D. (1993) “Called to account: the CV as an autobiographical Practice", Sociology, Vol. 21 No. 1, pp. 133-143.

Morrison, A. (2014), “You have to be well spoken': students' views on employability within the graduate labour market" Journal of Education and Work, Vol. 27 No. 2, pp. 179-198.

O'Connor, H. and Bodicoat, M. (2016), “Exploitation or Opportunity?: Student Perceptions of Internships in Enhancing Employability Skills", British Journal of Sociology of Education, doi.org/10.1080/01425692.2015.1113855

Putnam (1999) Bowling alone, Touchstone Books, New York.

Roulin, N. \& Bangerter, A. (2013), “Students' use of extra-curricular activities for positional advantage in competitive job markets", Journal of Education and Work, Vol. 26 No. 1, pp.21-47.

Savickas, M.L. \& Porfeli, E.J. (2012), “Career Adapt-Abilities Scale: Construction, reliability and measurement equivalence across 13 countries", Journal of Vocational Behaviour, Vol. 80, pp. $661-673$

Seligman, M. (1998), Learned optimism, Pocket Books, NY, New York.

Social Mobility and Child Poverty Commission (2013), Higher Education: the Fair Access Challenge, London: SMCPM.

Stevenson, J,. \& Clegg, S. (2012), "Who cares? Gender dynamics in the valuing of extra-curricular activities in higher education", Gender and Education, Vol. 24 No. 1, pp. 41-55.

Strangleman, T. (2012), "Work identity in crisis? Rethinking the problem of attachment and loss at work, Sociology, Vol 46 No. 3, pp. 411-425.

Tomlinson, M. (2007), "Graduate employability and student attitudes and orientations to the labour market", Journal of Education and Work, Vol. 20 No. 4, pp. 285-304.

Tomlinson, M. (2012), "Graduate employability: a review of conceptual and empirical themes", Higher Education Policy, Vol. 25 No. 4, pp. 407-431.

Wilton, N. (2011), “Do employability skills really matter in the UK graduate labour market? The case the business and management graduates", Work, Employment and Society, Vol. 25 No. 1, pp. 85-100. 
Wilton, N. (2012), "The impact of work placements on graduate skills development and career outcomes for business and management graduates", Studies in Higher Education, Vol. 37 No. 5, pp. 603-620. 


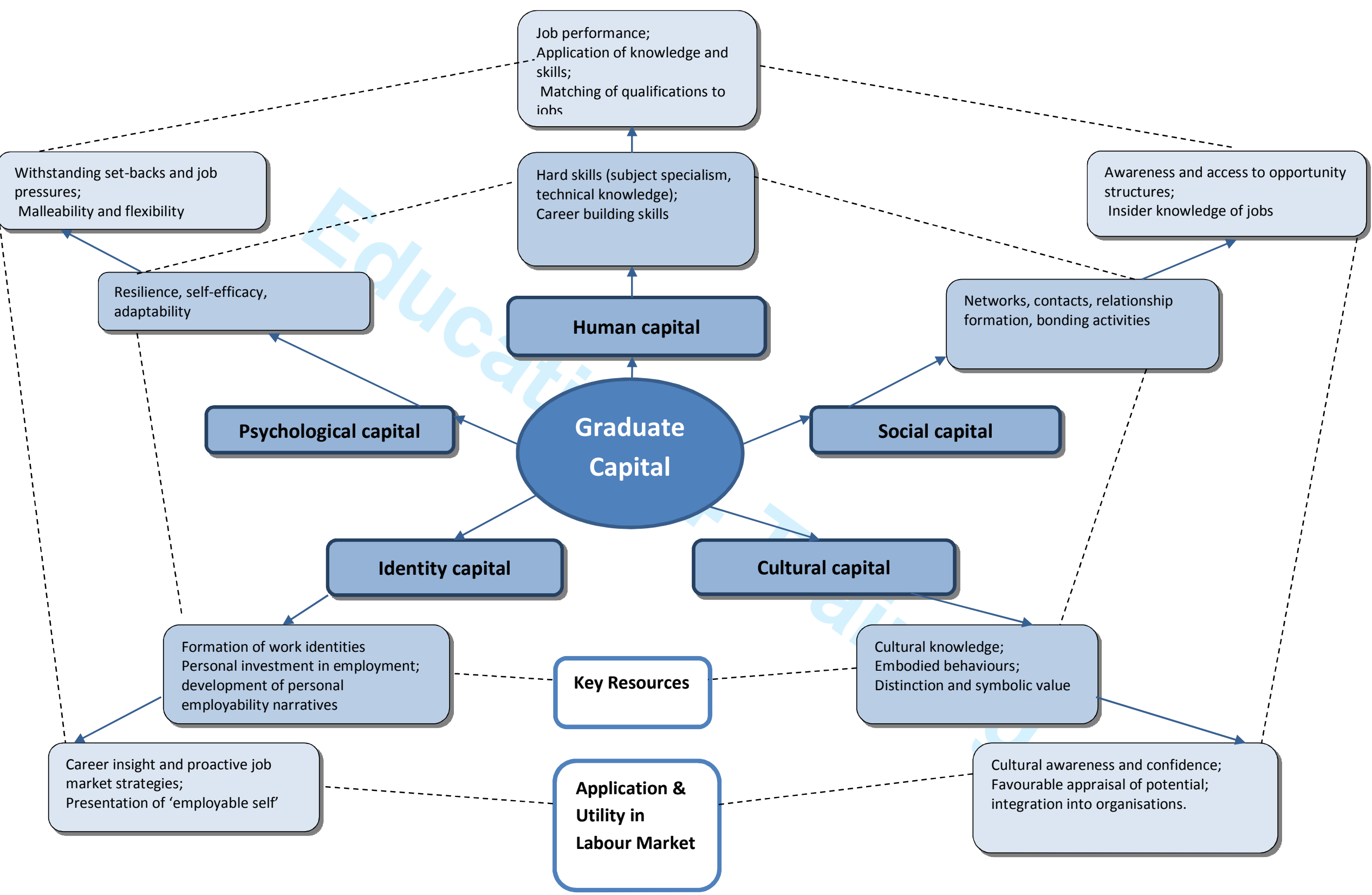

